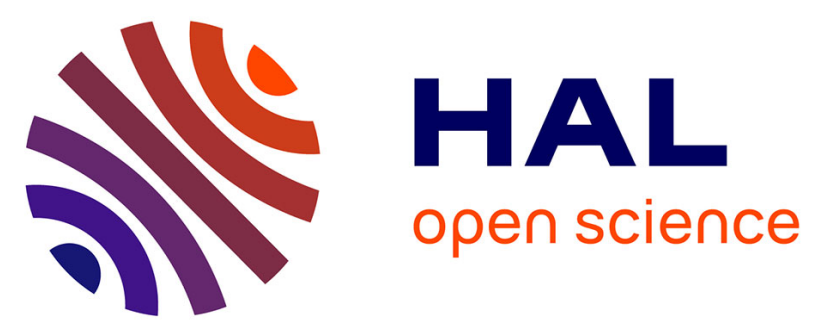

\title{
An anisotropic model with linear perturbation technique to predict HCP sheet metal ductility limit
}

\author{
Mohamed Yassine Jedidi, Mohamed Ben Bettaieb, Farid Abed-Meraim, \\ Mohamed Taoufik Khabou, Anas Bouguecha, Mohamed Haddar
}

\section{- To cite this version:}

Mohamed Yassine Jedidi, Mohamed Ben Bettaieb, Farid Abed-Meraim, Mohamed Taoufik Khabou, Anas Bouguecha, et al.. An anisotropic model with linear perturbation technique to predict HCP sheet metal ductility limit. International Conference on Advanced Materials Mechanics and Manufacturing (A3M 2021), Mar 2021, Sfax, Tunisia. hal-03251462

\section{HAL Id: hal-03251462 \\ https://hal.science/hal-03251462}

Submitted on 7 Jun 2021

HAL is a multi-disciplinary open access archive for the deposit and dissemination of scientific research documents, whether they are published or not. The documents may come from teaching and research institutions in France or abroad, or from public or private research centers.
L'archive ouverte pluridisciplinaire HAL, est destinée au dépôt et à la diffusion de documents scientifiques de niveau recherche, publiés ou non, émanant des établissements d'enseignement et de recherche français ou étrangers, des laboratoires publics ou privés. 


\title{
An anisotropic model with linear perturbation technique to predict HCP sheet metal ductility limit
}

\author{
Mohamed Yassine JEDIDI ${ }^{1,2}$, Mohamed BEN BETTAIEB ${ }^{2,3}$, Farid ABED- \\ MERAIM $^{2,3}$, Mohamed Taoufik KHABOU ${ }^{1}$, Anas BOUGUECHA ${ }^{1}$, Mohamed \\ HADDAR $^{1}$ \\ ${ }^{1}$ Laboratoire de Mécanique, Modélisation et de Production (LA2MP), École Nationale d'Ingénieurs de \\ Sfax (ENIS), Route Soukra Km 3.5 \\ mohamed-yasine.jdidi@enis.tn,mtkhabou@hotmail.com, anas.bouguecha@gmx.de, \\ mohamed.haddar@enis.rnu.tn \\ ${ }^{2}$ Arts et Métiers ParisTech, Université de Lorraine, CNRS, LEM3, F-57000, France \\ ${ }^{3}$ DAMAS, Laboratory of Excellence on Design of Alloy Metals for low-mAss Structures, Université de \\ Lorraine, France \\ mohamed.benbettaieb@ensam.eu, farid.abed-meraim@ensam.eu
}

\begin{abstract}
In this paper, hexagonal closed packed (HCP) sheet metal ductility for a viscoplastic material is analyzed by using a linear perturbation technique. It can be used for the analysis of localized necking. This technique is used to perturbate the material behavior in a rate dependent formulation by superimposing a perturbation to the basic flow which its stability or instability is characterized by the increasing or decreasing of the perturbation. Hardening and initial anisotropic parameters are fitted by experimental results from the literature. In this investigation, Cazacu yield function is used to predict the forming limit diagrams (FLDs) of HCP sheet metals. The coupling between analytic perturbation method and the behavior modelling is provided by an efficient implicit algorithm to solve the constitutive equations. After verifications and validations of the numerical simulations from the literature, the ductility limit of a particular HCP magnesium alloy is numerically predicted. A parametric study is presented to analyze the effect of instability and mechanical parameters, viscosity and distortion on the FLDs. Moreover, a comparative study between Marciniak and Kuckzynski ductility approach and linear perturbation technique is done in this contribution.
\end{abstract}

Keywords: necking criteria; plastic instabilities; forming limit diagrams; hexagonal closed packed material; behavior modelling; linear perturbation technique.

\section{Introduction}

Formability in sheet metal forming process is required in many engineering applications (aircraft, aerospace, automotive, etc.) to predict its ductility limit. Furthermore, several theoretical works were developed to predict the well-knowns forming limit diagrams (FLDs). This concept will be carried out using a coupling between instability necking criterion and one or more than one phenomenological model. In fact, several instability criteria are developed to predict the occurrence of plastic instability in thin sheet metals. The well-used approach has been inves- 
Mohamed Yassine JEDIDI, Mohamed BEN BETTAIEB, Farid ABED-MERAIM, Mohamed Taoufik KHABOU, Anas BOUGUECHA, Mohamed HADDAR

tigated by Marciniak and Kuckzynski (1967) which is called in the rest of the current paper by M-K. They have been introduced an initial geometric imperfection in order to obtain a theoretical complete FLD based on heterogeneous continuum model. This necking criterion is based on the comparison of the strain rate in expansion domain only. Several studies (Molinari, 1985; Dudzinski and Molinari, 1991; Boudeau and Gelin, 1992, etc.) have been used a homogeneous continuum model where the necking is perturbed to be an instability of the mechanical equilibrium state. This alternative approach is called the linear perturbation analysis.

It is used to predict the FLD by imposing a geometrical defect which generates to an imperfection on principal strain rates. This technique leads to a linear perturbation at certain stage of deformation process of the thin sheet metals which are assumed to be initially homogeneous.

Several contributions are investigated in last decades based on linear perturbation technique. Fressengeas and Molinari (1987) have been used the classical perturbation technique (Molinari, 1985) taking into account the heat conduction to evolve the instability and localization effects of the plastic flow in shear at high strain rates. Perturbation analysis is used analytically to predict FLDs for quite general material behavior based on their viscoplastic instabilities in bi-axial loading (Dudzinski and Molinari, 1991). The ductility limit has been predicted by Toth et al., 1996 using stress potential function for viscoplastic material. A computational prediction of the localized necking has been executed by Boudeau et al (1998) based on micro-structural material aspects using perturbation analysis. Boudeau et al (2002) have been extended the linear stability analysis to 3 dimensions (3D) stress states to allows the detection of defects during hydro-forming process. Recently, Zaera et al (2015) have been investigated the spacing between necking bands in sheet thermo-viscoplastic metals based on linear perturbation technique within a $2 \mathrm{D}$ framework.

All previous investigations are dedicated especially for body centered cubic materials (BCC) and face centered materials (FCC). Hexagonal closed packed materials (HCP) have been used recently by several researchers due to their mechanical characteristics (lightweight, high specific strength, high fatigue resistance, etc.). In last decades, several researchers have been predicted the ductility limit of HCP materials (Wu et al., 2015; Kondori et al., 2018 ...) at room temperature. However, ductility limit predictions for $\mathrm{HCP}$ materials at room temperature are presented in limited works from the literature (Wu et al.., 2015; Kondori et al., 2018...). Despite the limitation of ductility for HCP materials, many researchers have succeeded to model its mechanical behavior (Cazacu et al., 2006; Plunkett et al., 2006...) in order to predict its ductility limit (Jedidi et al., 2020-a; Jedidi et al., 2020-b...), at room temperature.

The onset of localized necking of HCP materials is predicted numerically in the literature generally by $\mathrm{M}-\mathrm{K}$ analysis and bifurcation. In the current paper, the onset of localized necking of HCP sheet metals is predicted for the first time using the linear perturbation technique of Dudzinski and Molinari (1991) to assess and validate our numerical simulations. The constitutive model of Cazacu et al., 2006 is used at room temperature to model the mechanical behavior of HCP materials. 


\section{An anisotropic model with non-associated flow rule to predict HCP sheet}

A brief outline of this paper is presented by 5 sections. We have dedicated the section 2 of this paper to the constitutive framework to model the mechanical behavior of HCP materials as well as the main equations which leads to define the linear perturbation technique, whereas section 3 outlines the numerical implementation of the M-K instability criterion and constitutive equations of section 2 . The section 4 provides the validation of the developed model and the numerical investigation. Then, it presents a comparative study to analyze viscosity and distortion effects, and to show the difference between linear perturbation technique and the M-K approach in terms of FLDs. Finally, section 5 closes the present contribution by some conclusions and perspectives.

\section{Theoretical framework}

\subsection{Constitutive model}

Due to the twinning mechanism which leads to tension-compression asymmetry of the stress rate for HCP materials, the behavior modelling is estimated in this paper, by the yield locus of Cazacu et al (2006) and briefly called CPB06. This model is expressed by the equivalent plastic stress:

$$
\widehat{\sigma}=B\left(\left(\left|\Sigma_{1}\right|-k \Sigma_{1}\right)^{a}+\left(\left|\Sigma_{2}\right|-k \Sigma_{2}\right)^{a}+\left(\left|\Sigma_{3}\right|-k \Sigma_{3}\right)^{a}\right)^{1 / a}
$$

where $B$ is a material parameter, $k$ describes the asymmetry of the deformation behavior, $\Sigma_{1}, \Sigma_{1}$ and $\Sigma_{1}$ are the eigenvalues of the linear transformation $\Sigma$ equals to $\mathbf{L}: \mathbf{T}: \sigma$ such as $\mathbf{L}$ is the fourth-order transformation tensor and $\mathbf{T}$ is the passage matrix:

$\mathbf{L}=\left(\begin{array}{cccccc}L_{11} & L_{12} & L_{13} & 0 & 0 & 0 \\ L_{12} & L_{22} & L_{23} & 0 & 0 & 0 \\ L_{13} & L_{23} & L_{33} & 0 & 0 & 0 \\ 0 & 0 & 0 & L_{44} & 0 & 0 \\ 0 & 0 & 0 & 0 & L_{55} & 0 \\ 0 & 0 & 0 & 0 & 0 & L_{66}\end{array}\right), \mathbf{T}=\frac{1}{3}\left(\begin{array}{cccccc}2 & -1 & -1 & 0 & 0 & 0 \\ -1 & 2 & -1 & 0 & 0 & 0 \\ -1 & -1 & 2 & 0 & 0 & 0 \\ 0 & 0 & 0 & 3 & 0 & 0 \\ 0 & 0 & 0 & 0 & 3 & 0 \\ 0 & 0 & 0 & 0 & 0 & 3\end{array}\right)$

In this investigation, the hardening law is supposed isotropic, isochoric and obeys to the normality law. Moreover, the assumption of a rigid visco-plastic material is done. The Swift hardening law used in this work is presented by: 
Mohamed Yassine JEDIDI, Mohamed BEN BETTAIEB, Farid ABED-MERAIM, Mohamed Taoufik KHABOU, Anas BOUGUECHA, Mohamed HADDAR

$\sigma_{y}=\tilde{\sigma}=K\left(\varepsilon_{0}+\widehat{\varepsilon}\right)^{n}(\dot{\bar{\varepsilon}})^{m}$,

where $\widehat{\varepsilon}$ is the equivalent strain and $\dot{\vec{\varepsilon}}$ the equivalent strain rate, $K$ the hardening parameter, $n$ the hardening exponent and $m$ is the rate sensitivity exponent.

The constitutive relation between the strain rate and its equivalent is expressed in this contribution by the associated flow rule using the normal vector on the yield locus $\partial \hat{\sigma} / \partial \sigma$ :

$\dot{\varepsilon}=\dot{\widehat{\varepsilon}} \frac{\partial \hat{\sigma}}{\partial \sigma}$

\subsection{Linear perturbation technique}

The principle of the perturbation technique is described as shown in fig. 1. Note that $x_{1}-x_{2}$ is a plane coordinate system which is referred for wavy line. The second coordinate system $x-y$ refers the sheet metal. Two parameters characterize geometrically the instability mode; the angle orientation $\psi$ of $x_{1}-x_{2}$ and the wave number $\xi$. Thus, the perturbation is described as below:

$\delta \mathbf{P}=\delta \mathbf{P}^{0} \exp \left(\eta\left(t-t_{0}\right) \exp \left(i \xi . x_{1}\right)\right)$,

where the isotropic yield stress $\sigma^{i s o}(\gamma)$ is a function of the equivalent plastic strain given by the Swift equation as following: where $\left(t-t_{0}\right)$ is the time of the perturbation and $\eta$ is the rate of the growth of the perturbation knowing that if $\operatorname{Re}\left(\frac{\eta}{\dot{\bar{\varepsilon}}}\right)<0 \Rightarrow$ stability and if $\operatorname{Re}\left(\frac{\eta}{\dot{\bar{\varepsilon}}}\right)>0 \Rightarrow$ instability. The perturbation described in eq. (5) leads to obtain the homogeneous solution in the rotated frame. However, this solution requires equilibrium equations, compatibility and incompressibility conditions.

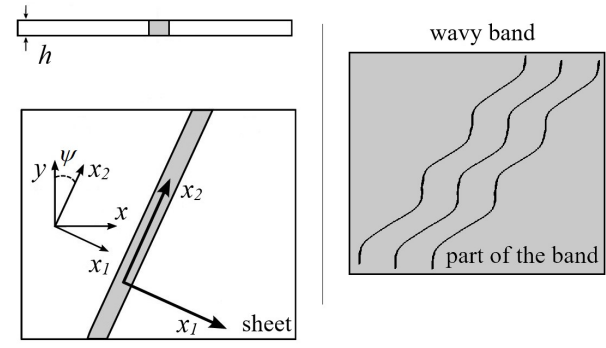

Fig.1. Linear perturbation in thin sheet metal. 
An anisotropic model with non-associated flow rule to predict HCP sheet metal ductility limit

In case of long wave perturbation and plane stress condition (fig. 1) the equilibrium equation are:

$\operatorname{div}(h \sigma)=\mathbf{0} \Leftrightarrow\left\{\begin{array}{l}\frac{\partial\left(h \sigma_{11}\right)}{\partial x_{1}}+\frac{\partial\left(h \sigma_{12}\right)}{\partial x_{2}}=0 \\ \frac{\partial\left(h \sigma_{12}\right)}{\partial x_{1}}+\frac{\partial\left(h \sigma_{22}\right)}{\partial x_{2}}=0\end{array}\right.$,

where $h$ equals to $h_{0} \exp \left(\varepsilon_{33}\right)$ is the current thickness of the thin sheet metal, $h_{0}$ is the initial thickness and $\varepsilon_{33}$ is related to $\varepsilon_{11}$ and $\varepsilon_{22}$ within incompressibility condition.

Aside the equilibrium equation to the homogeneous solution, the compatibility condition can be expressed as:

$\frac{\partial^{2} \dot{\varepsilon}_{11}}{\partial x_{2}^{2}}+\frac{\partial^{2} \dot{\varepsilon}_{11}}{\partial x_{1}^{2}}=2 \frac{\partial^{2} \dot{\varepsilon}_{12}}{\partial x_{1} \partial x_{2}}$,

and the incompressibility condition in the rotated reference system is expressed as:

$\dot{\varepsilon}_{11}+\dot{\varepsilon}_{22}+\dot{\varepsilon}_{33}=0$

Based on the investigation of Dudzinski and Molinari (1991) and Toth et al (1996), strain rates $\dot{\varepsilon}_{11}, \dot{\varepsilon}_{22}$ and $\dot{\varepsilon}_{33}$ can be expressed in the fixed coordinate system $x_{1}-x_{2}$ by:

$\dot{\varepsilon}_{x x}=\dot{\widehat{\varepsilon}} \frac{\partial \hat{\sigma}}{\partial \sigma_{x x}}=\dot{\vec{\varepsilon}} T_{x x}$

$\dot{\varepsilon}_{y y}=\dot{\widehat{\varepsilon}} \frac{\partial \hat{\sigma}}{\partial \sigma_{y y}}=\dot{\widehat{\varepsilon}} T_{y y}$,

$\dot{\varepsilon}_{x y}=\dot{\widehat{\varepsilon}} \frac{\partial \hat{\sigma}}{\partial \sigma_{x y}}=\dot{\widehat{\varepsilon}} T_{x y}$.

However, the flow law in the rotated reference system has to be expressed by:

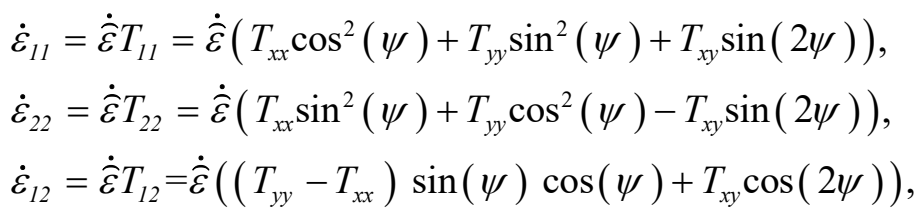


Mohamed Yassine JEDIDI, Mohamed BEN BETTAIEB, Farid ABED-MERAIM, Mohamed Taoufik KHABOU, Anas BOUGUECHA, Mohamed HADDAR

Cauchy stress are also described in the rotated frame by:

$$
\begin{aligned}
& \sigma_{11}=\sigma_{x x} \cos ^{2}(\psi)+\sigma_{y y} \sin ^{2}(\psi)+\sigma_{x y} \sin (2 \psi), \\
& \sigma_{22}=\sigma_{x x} \sin ^{2}(\psi)+\sigma_{y y} \cos ^{2}(\psi)-\sigma_{x y} \sin (2 \psi), \\
& \sigma_{12}=\left(\sigma_{y y}-\sigma_{x x}\right) \sin (\psi) \cos (\psi)+\sigma_{x y} \cos (2 \psi) .
\end{aligned}
$$

Using all previous equations, the homogeneous solution in the rotated frame at time $t_{0}$ is a vector which contains 10 initial values. Thus, this vector is given by:

$$
\mathbf{P}^{0}=\left(\dot{\varepsilon}_{11}^{0}, \dot{\varepsilon}_{22}^{0}, \dot{\varepsilon}_{33}^{0}, \dot{\varepsilon}_{12}^{0}, \sigma_{11}^{0}, \sigma_{22}^{0}, \sigma_{12}^{0}, \widehat{\sigma}^{0}, \dot{\bar{\varepsilon}}^{0}, h^{0}\right)
$$

Due to this relation: $h=h_{0} \exp \left(\varepsilon_{33}\right)$, the thickness $h$ can be eliminated. Thus, for each value of the angle orientation $\psi$, the unknown vector $\mathbf{P}$ contains 9 initial values without considering the thickness $h$.

At $t=t_{0}$, the homogeneous solution is tested by superposing small perturbations $\delta \mathbf{P}$. Therefore, components of the perturbed solution $\mathbf{P}$ equals to $\mathbf{P}^{0}+\delta \mathbf{P}^{0} \exp \left(\eta\left(t-t_{0}\right) \exp \left(i \xi . x_{1}\right)\right)$ are:

$\dot{\varepsilon}_{11}=\dot{\varepsilon}_{11}^{0}+\delta \dot{\varepsilon}_{11}, \dot{\varepsilon}_{22}=\dot{\varepsilon}_{22}^{0}+\delta \dot{\varepsilon}_{22}, \dot{\varepsilon}_{33}=\dot{\varepsilon}_{33}^{0}+\delta \dot{\varepsilon}_{33}, \dot{\varepsilon}_{12}=\dot{\varepsilon}_{12}^{0}+\delta \dot{\varepsilon}_{12}$,

$\sigma_{11}=\sigma_{11}^{0}+\delta \sigma_{11}, \sigma_{22}=\sigma_{22}^{0}+\delta \sigma_{22}, \sigma_{12}=\sigma_{12}^{0}+\delta \sigma_{12}$.

where $\delta \mathbf{P}^{0}=\left(\delta \dot{\varepsilon}_{11}^{0}, \delta \dot{\varepsilon}_{22}^{0}, \delta \dot{\varepsilon}_{33}^{0}, \delta \dot{\varepsilon}_{12}^{0}, \delta \sigma_{11}^{0}, \delta \sigma_{22}^{0}, \delta \sigma_{12}^{0}, \delta \hat{\sigma}^{0}, \delta \dot{\vec{\varepsilon}}^{0}, \delta h^{0}\right)$ is the polarization vector.

Due to linearization of the previous equations, the vector polarization is supposed as solution of the nine equations already calculated and presented by Toth et al (1996). Based on their investigation, a non-linear operator called $\mathbf{O}$ is a function of the perturbed vector. This non-linear system is linearized by neglecting the exponential part of the perturbation. This is due to the small perturbation at the initial stage compared by the regular solution. Thus, the non-linear function $\mathbf{O}$ is described by:

$$
\mathbf{O}(\mathbf{P})=\mathbf{O}\left(\mathbf{P}^{0}+\delta \mathbf{P}^{0} \exp \left(\eta\left(t-t_{0}\right) \exp \left(i \xi . x_{1}\right)\right)\right)=\mathbf{O}\left(\mathbf{P}^{0}+\delta \mathbf{P}^{0}\right)
$$

This leads to the following linear system:

$$
\mathbf{M}\left(\mathbf{P}^{0}, \eta_{c}, \psi\right) \cdot \delta \mathbf{P}^{0}=\mathbf{0} .
$$


An anisotropic model with non-associated flow rule to predict HCP sheet metal ductility limit

where $\eta_{c}=\frac{\eta}{\dot{\hat{\varepsilon}}}$ and $\mathbf{M}$ is a matrix made up based on nine equations in the work of Toth et al (1996). A, the regular solution is obtained when $\operatorname{det}\left(\mathbf{M}\left(\mathbf{P}^{0}, \eta_{c}, \psi\right) \cdot \delta \mathbf{P}^{0}\right)=\mathbf{0}$, to give finally the polynomial equation which is a function of $\psi$ and $\eta_{c}$ :

$\eta_{c}\left[a(\psi) \eta_{c}^{2}+b(\psi) \eta_{c}+c(\psi)\right]=0$,

where components of $a(\psi), b(\psi)$ and $c(\psi)$ are described with details in the contribution of (Toth et al., 1996).

For each angle orientation $\psi$, three values of $\eta_{c}$ are obtained. The $\eta_{c}=0$ is a possible solution, however, it is neglected because it does not occur a growing instability. Moreover, two other solutions of $\eta_{c}$ are generally complex. To pass from stability to instability, one of the three roots has a positive real part; $\operatorname{Re}\left(\eta_{c}\right) \geq e$ where $e$ is the effective instability parameter (Dudzinski and Molinari, 1991). Note that if $e=0$, the absolute instability is observed. Based on the work of Dudzinski and Molinari (1991), several values of $e(0<e<25)$ leads to an instability. For each angle orientation, we obtain the strain value which the material can be deformed. To characterize the critical strain value $\varepsilon^{c}$ and the optimal orientation of the band $\psi^{c}$, we minimize the strain value by the absolute value $\varepsilon^{a}$ :

$\varepsilon^{a}(e, \rho)=\min \left(\varepsilon^{c}(e, \rho, \psi)\right)=\varepsilon^{c}\left(e, \rho, \psi^{c}\right)$.

It is very important to note that Dudzinski and Molinari (1991) has been shown that general bifurcation is obtained when the effective parameter $e \rightarrow \infty$ and the rate sensitivity exponent equal zero. After the definition of perturbation technique theoretically, numerical implementation is clearly presented in section 3 .

\section{Implicit incremental algorithm}

The prediction of the ductility limit for viscoplastic material using the linear perturbation analysis is clearly described as below:

Step 1: calculate $\frac{\partial \sigma^{2}}{\partial \sigma_{i j} \partial \sigma_{k l}}$ to obtain eq. 18. This step is based on the derivative formulation described in the appendix of the contribution of Jedidi et al (2020-b).

Step 2: solve the following four equations from the integration code to calculate Cauchy stress components and the equivalent plastic strain: 
Mohamed Yassine JEDIDI, Mohamed BEN BETTAIEB, Farid ABED-MERAIM, Mohamed Taoufik KHABOU, Anas BOUGUECHA, Mohamed HADDAR

$\Delta \boldsymbol{\varepsilon}=\Delta \widehat{\varepsilon} \frac{\partial \widehat{\sigma}}{\partial \sigma} \rightarrow \sigma_{11}=? ; \sigma_{22}=? ; \sigma_{12}=?$

$\sigma: \Delta \boldsymbol{\varepsilon}=\Delta \widehat{\varepsilon} . \widehat{\sigma} \rightarrow \widehat{\varepsilon}=?$.

In this step, we obtain $\mathbf{P}=\left(\dot{\varepsilon}_{11}, \dot{\varepsilon}_{22}, \dot{\varepsilon}_{33}, \dot{\varepsilon}_{12}, \sigma_{11}, \sigma_{22}, \sigma_{12}, \widehat{\sigma}, \dot{\bar{\varepsilon}}\right)$.

Step 3: consider the previous solutions as initial solution in perturbed equations. Thus, the initial solution $\mathbf{P}^{0}$ to begin the perturbation is equal to $\mathbf{P}$. Moreover, the resolution of the new solution $\mathbf{P}$ is based these contributions (Toth et al., 1996; Jedidi et al., 2020-b), and the previous equations from 1 to 16.

Step 4: solve the polynomial equation for each increment and each angle orientation. This step describes the resolution of the polynomial equation (Eq. 18) for $\psi$ from $0^{\circ}$ to $90^{\circ}$.

Step 5: if the instability condition is observed for an iteration and a strain path, iterative calculation is stopped. Thus, for each $\psi$, if $\eta_{c}>e$ and $\frac{n}{\dot{\varepsilon}}<1 \rightarrow$ calculation is stopped.

The prediction of FLDs is ensured by means a two nested loops of an efficient algorithm implemented in the multi-paradigm, numerical computing environment Mathematica, as shown as below:

- For the strain path ratio $\rho=-1 / 2$ to $\rho=1$ with $\Delta \rho=0.1$.

- For $t=t_{0}$ to $t=t_{n+1}$ with $t_{n+1}=t_{n}+\Delta t$ and $\Delta t$ is the time increment $\left[t_{n}, t_{n+1}\right]$.

- Apply the implicit incremental algorithm described in the previous section. If $\hat{\eta}>e$ and $\frac{n}{\dot{\varepsilon}}<1 \rightarrow$ the implicit algorithm is stopped.

- Over all possible initial angles, $\varepsilon_{11}^{c}=\min \left\{\varepsilon_{11}\right\}$ and $\varepsilon_{22}^{c}=\rho \varepsilon_{11}^{c}$ where $\varepsilon_{11}^{c}$ and $\varepsilon_{22}^{c}$ are the major and minor localization limit strains.

\section{Results and discussions}

To predict the FLD of HCP materials, Cazacu yield criterion is chosen in this investigation (CPB06) as the constitutive model. This yield criterion is extremely dependent to anisotropic parameters of the material. Magnesium-Lithium alloy $(\mathrm{Mg}-\mathrm{Li}(4 \% \mathrm{Li}))$ is used in our contribution to predict FLDs. However, before using this alloy, we should validate our work. Dudzinski and Molinari (1991) have 
An anisotropic model with non-associated flow rule to predict HCP sheet metal ductility limit

been used an isotropic material which its isotropic parameters are $K=120 \mathrm{MPa}$, $n=0.25$ and $\varepsilon_{0}=0$.

Fig.2 presents a comparison between the FLD predicted numerically by our simulation and the FLD predicted by Dudzinski and Molinari (1991). It is very clear that the ductility limit for anisotropic material is in good agreement with the work of Dudzinski and Molinari (1991) for uni-axial tensile test. For plane strain and biaxial loading, a small difference between FLDs is clearly shown in fig.2-a which can be due to the method of the implementation of the linear perturbation technique in our numerical simulations. Fig.2-b presents for a viscous isotropic material, the evolution of the positive real part of the root solved from eq. 18. This evolution is represented versus the strain $\varepsilon_{11}$ for plane strain $(\rho=0)$. A good correlation is shown in this figure (fig.2-b) between the work of Dudzinski and Molinari (1991) and our numerical predictions. Thus, our numerical simulations are assessed and validated with the work of Dudzinski and Molinari (1991).

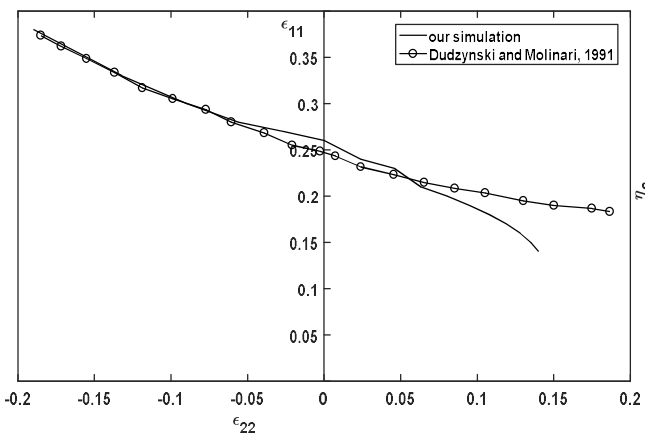

(a): Forming limit diagrams $(\mathrm{m}=0)$

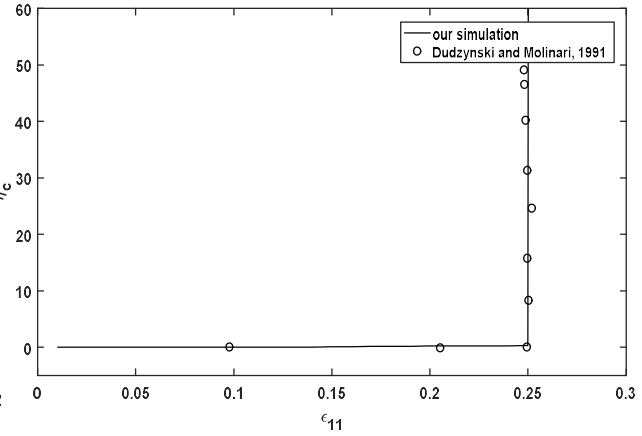

(b): Evolution of the rate $\eta_{c} \quad(\mathrm{~m}=10-5)$

Fig.2. Comparison between numerical simulations and the work of Dudzinski and Molinari 1991

After validation of our numerical model, we predict in this contribution the ductility limit for Mg-Li 4\% which is soft and ductile. The choose of HCP material in this work is dependent on experimental results to predict anisotropic parameters of CPB06. A fitting method is used in a numerical implementation to predict anisotropic parameters from an experimental yield locus. Thus, our investigation is based on experimental results of Cazacu et al (2006) for the $\mathrm{Mg}-\mathrm{Li}(4 \% \mathrm{Li})$ as shown in fig.3. This figure (Fig.3) presents a good correlation between our fitted yield surface and experimental points. This good agreement signifies that our fitted anisotropic parameters are validated for the $\mathrm{Mg}-\mathrm{Li} 4 \%$. 
Mohamed Yassine JEDIDI, Mohamed BEN BETTAIEB, Farid ABED-MERAIM, Mohamed Taoufik KHABOU, Anas BOUGUECHA, Mohamed HADDAR

Table 1. Material parameters for the $\mathrm{Mg}-\mathrm{Li}(4 \% \mathrm{Li})$ magnesium alloy (stress-like parameters are expressed in $\mathrm{MPa}$ ).

\begin{tabular}{|c|c|c|c|c|c|c|}
\hline Hardening & $K$ & $n$ & $\varepsilon_{0}$ & & & \\
\cline { 2 - 7 } & 405.26 & 0.166 & 0.0015 & & & \\
\hline \multirow{2}{*}{ Anisotropy } & $L_{11}^{C}$ & $L_{22}^{C}$ & $L_{33}^{C}$ & $L_{12}^{C}$ & $L_{23}^{C}$ & $L_{13}^{C}$ \\
\cline { 2 - 7 } & 1 & 0.9783 & 0.1648 & 0.6114 & 0.2479 & 0.7819 \\
\hline & $L_{44}^{C}$ & $L_{55}^{C}$ & $L_{66}^{C}$ & $a$ & $k$ & \\
\cline { 2 - 7 } & 1 & 1 & 1 & 2 & 0.2126 & \\
\hline
\end{tabular}

Numerical predictions of fitting based on experimental results gives the anisotropic and swift hardening parameters based on CPB06 as shown in table 1. We note that hardening parameters are fitted in this contribution based on the experimental hardening curve of Bochniak et al (2018).

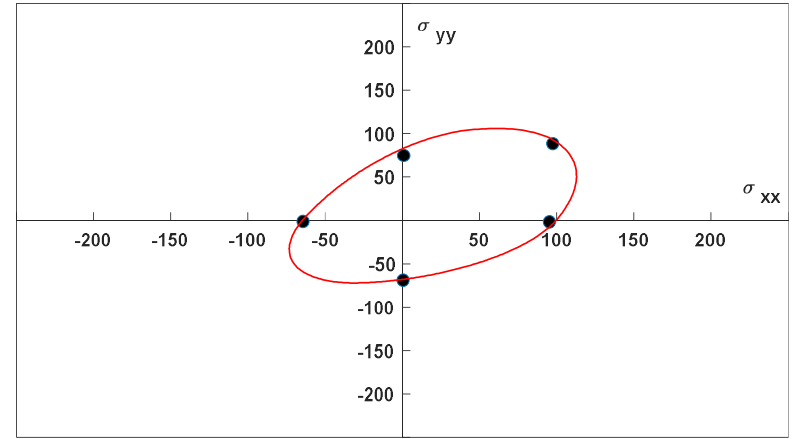

Fig.3. Experimental (points) and fitted (lines) yield locus of $\mathrm{Mg}-\mathrm{Li}(4 \% \mathrm{Li})$

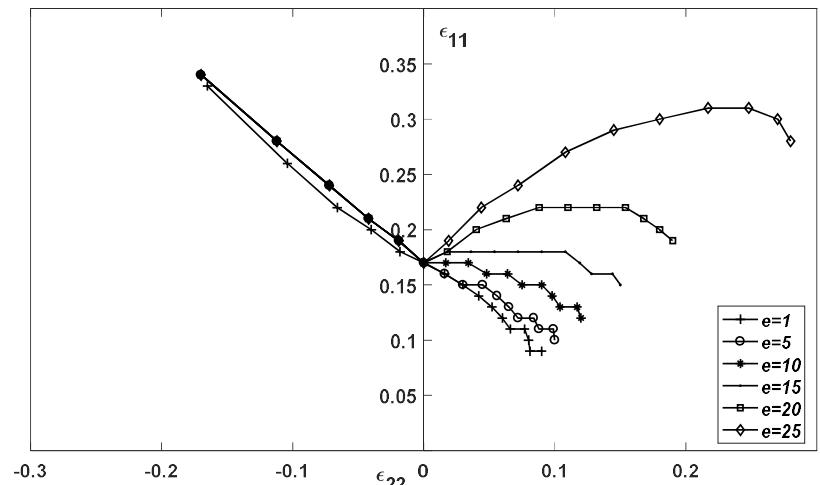

Fig.4. Effect of instability parameter $e$ on FLDs 
An anisotropic model with non-associated flow rule to predict HCP sheet metal ductility limit

Validation of our numerical simulations and fitting of anisotropic parameters based on experimental results allow to predict the ductility limit of the magnesium alloy Mg-Li 4\%. Forming limit diagrams predicted by the coupling between CPB06 yield criterion and linear perturbation method are strongly dependent on the effective instability parameter $e$. this parameter can be varied between 1 and 25 , thus, we can obtain an infinity of FLDs as presented in fig.4. In this paper, a reasonable value $(e=20)$ is fixed for the rest of this paper.

In order to enhance the behavior modelling of the magnesium alloy $\mathrm{Mg}-\mathrm{Li} 4 \%$ in non-proportional loading, a modification of the classical CPB06 model including distortion of the yield surface is proposed. Thus, yield surface distortions depends on new material parameters at a variety of strains scales. Consequently, it is very important to identify distortion effects on FLDs.

A preliminary study is done to identify anisotropic parameters at a variety of strain scales $(1 \%, 5 \%$ and $10 \%$ in our contribution). This study is based on fitting using experimental results. Fitted anisotropic parameters presented in table. 2 allow to predict three yield surfaces at $1 \%, 5 \%$ and $10 \%$ of strain. In this paper, linear interpolation technique employed in Plunkett et al (2006) is used to predict anisotropic parameters for each value of strain to predict FLD using these three fitted yield surface.

Table 2. Material parameters for the $\mathrm{Mg}-\mathrm{Li}(4 \% \mathrm{Li})$ magnesium alloy at a variety of strain scales (stress-like parameters are expressed in $\mathrm{MPa}$ ).

\begin{tabular}{|c|c|c|c|c|c|c|}
\hline \multirow[t]{4}{*}{$\begin{array}{l}\text { Anisotropy: } \\
1 \% \text { of deformation }\end{array}$} & $L_{11}^{C}$ & $L_{22}^{C}$ & $L_{33}^{C}$ & $L_{12}^{C}$ & $L_{23}^{C}$ & $L_{13}^{C}$ \\
\hline & 1 & 0.9783 & 0.1648 & 0.6114 & 0.2479 & 0.7819 \\
\hline & $L_{44}^{C}$ & $L_{55}^{C}$ & $L_{66}^{C}$ & $a$ & $k$ & \\
\hline & 1 & 1 & 1 & 2 & 0.2126 & \\
\hline \multirow{4}{*}{$\begin{array}{l}\text { Anisotropy : } \\
5 \% \text { of deformation }\end{array}$} & $L_{11}^{C}$ & $L_{22}^{C}$ & $L_{33}^{C}$ & $L_{12}^{C}$ & $L_{23}^{C}$ & $L_{13}^{C}$ \\
\hline & 1 & 0.9783 & 0.2017 & 0.5492 & 0.4077 & 0.6056 \\
\hline & $L_{44}^{C}$ & $L_{55}^{C}$ & $L_{66}^{C}$ & $a$ & $k$ & \\
\hline & 1 & 1 & 1 & 2 & 0.2249 & \\
\hline \multirow[t]{4}{*}{$\begin{array}{l}\text { Anisotropy : } \\
10 \% \text { of deformation }\end{array}$} & $L_{11}^{C}$ & $L_{22}^{C}$ & $L_{33}^{C}$ & $L_{12}^{C}$ & $L_{23}^{C}$ & $L_{13}^{C}$ \\
\hline & 1 & 0.9783 & 0.6622 & 0.7590 & 0.8985 & 0.9305 \\
\hline & $L_{44}^{C}$ & $L_{55}^{C}$ & $L_{66}^{C}$ & $a$ & $k$ & \\
\hline & 1 & 1 & 1 & 2 & 0.0472 & \\
\hline
\end{tabular}


Mohamed Yassine JEDIDI, Mohamed BEN BETTAIEB, Farid ABED-MERAIM, Mohamed Taoufik KHABOU, Anas BOUGUECHA, Mohamed HADDAR

Fig. 5-a presents two forming limit diagrams with and without taking into account distortion of yield surface. Distortion has no effect on FLD in uni-axial tensile test and plane strain. However, the level and the shape of the FLD is sensitive to distortion in bi-axial stretching, especially for the strain path ratio $\rho$ equals more than 0.3 . This sensitivity to distortion allows the increasing of the ductility limit on the positive part of FLD. Nevertheless, distortion has almost no effect on the band orientation for all strain path ratio as shown in fig. 5-b.

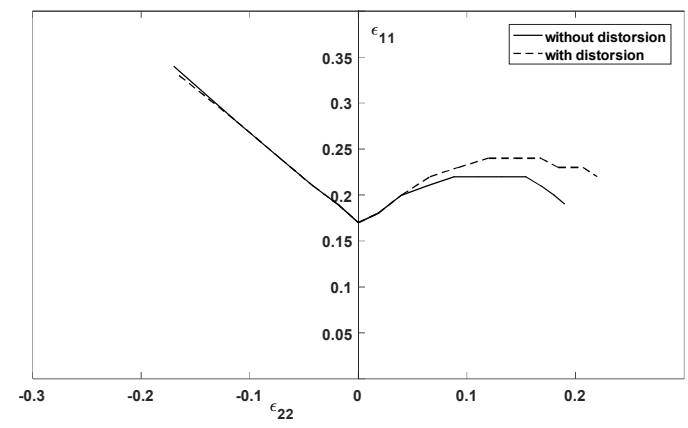

(a): Forming limit diagram

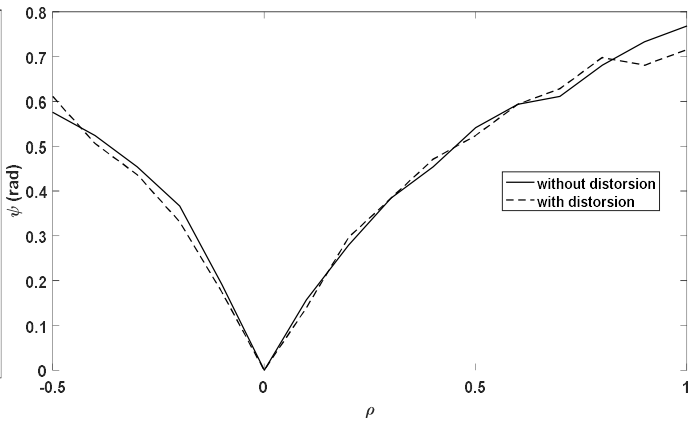

(b): Band orientation

Fig.5. Effect of distortion $(\mathrm{m}=0)$

Actually we intend to predict the onset of the localized necking in a $\mathrm{Mg}-\mathrm{Li} 4 \%$ magnesium sheet alloy using the M-K ductility approach. Our goal is to compare our FLD predicted by M-K approach with FLD predicted by linear perturbation technique. For M-K ductility approach, the used initial imperfection factor in this work equals to 0.995 .

Fig. 6-a shows a comparison between FLDs predicted by linear perturbation technique and $\mathrm{M}-\mathrm{K}$ ductility approach, respectively. A higher ductility of the $\mathrm{Mg}-\mathrm{Li}$ $4 \%$ magnesium alloy is obtained by the perturbation technique for all strain path ratio except the equi-biaxial stretching. This is due to the initial imperfection factor proposed by $\mathrm{M}-\mathrm{K}$ which increases the values of major strains, especially in biaxial stretching. Numerical simulations of the initial imperfection model take a huge calculation time to predict an FLD compared with the perturbation technique.

Effect of viscosity on FLDs is an important think for scientific researchers. For this reason, we predict in this work the ductility limit for plastic material and visco-plastic material using two different necking criteria (M-K ductility approach and linear perturbation technique).

Fig. 6-b presents two FLDs predicted by perturbation technique which have the same shape, but not the same level. It is clear that viscosity allow to increase the ductility limit of the material. This increase is due to the rate sensitivity exponent $\mathrm{m}$ of the equivalent strain rate. Thus, we obtain a highest hardening curve. The sensitivity of $\mathrm{m}$ on hardening allows to obtain highest values of major strain. Con- 
An anisotropic model with non-associated flow rule to predict HCP sheet metal ductility limit

sequently, we obtain highest level of FLD. Same conclusions describe the effect of viscosity on FLDs predicted by M-K ductility approach as shown in fig. 6-c.

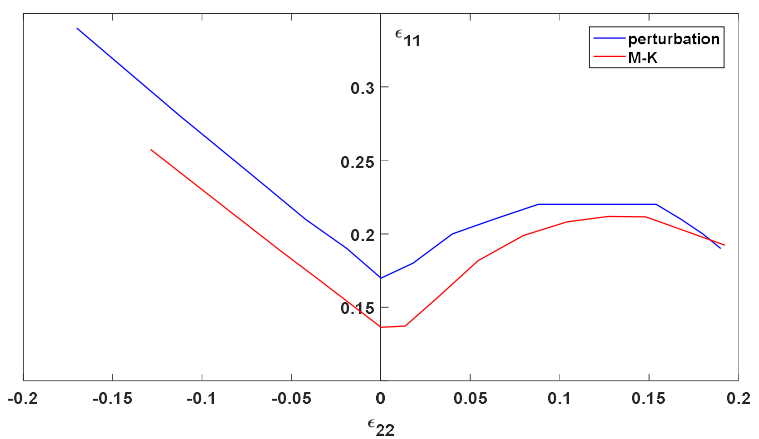

(a): Comparison between perturbation technique and M-K ductility (FLDs).

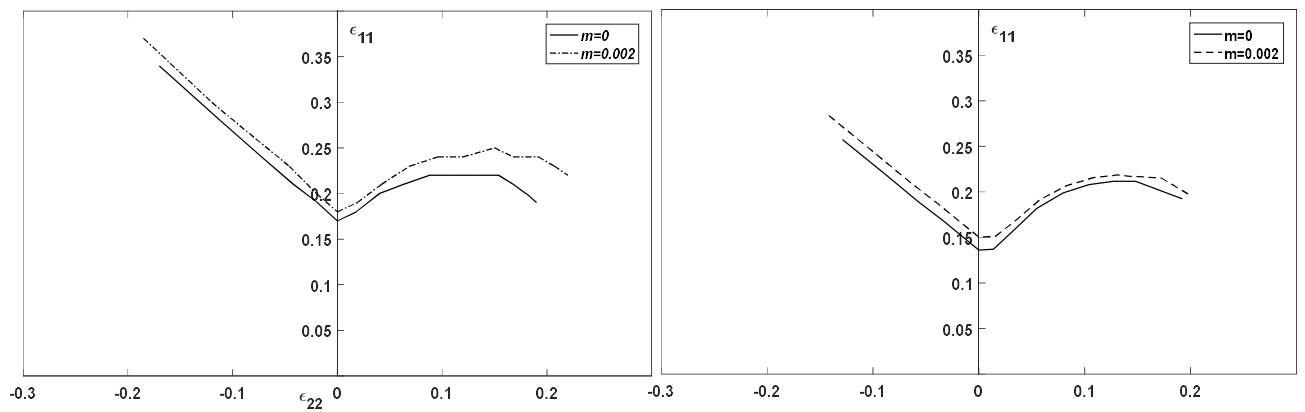

(b): Linear perturbation method

(c): M-K ductility approach

Fig.6. (a): Comparison between 2 necking criteria; (b) and (c): Effect of viscosity on FLD

\section{Conclusions}

In this paper, the problem of plastic instabilities in bi-axial sheet deformation is solved by using the linear perturbation technique. This technique was coupled with the phenomenological model presented in Cazacu et al. (2006) to predict the forming limit for the $\mathrm{Mg}-\mathrm{Li}$ 4\% magnesium alloy. Based on constitutive equations presented in this contribution, a robust numerical procedure is implemented to describe the linear perturbation technique. This numerical procedure is used in conjunction with two plastic instability criteria (the linear perturbation technique and the initial imperfection approach), to predict the onset of necking in HCP materials. From results of the numerical predictions, our simulations are assessed and validated with Dudzinski and Molinari (1991) for anisotropic material. After validation of our numerical results, a sensitivity study is conducted to analyze the effect of the instability parameter on the necking limit after fitting anisotropic parameters of the $\mathrm{Mg}-\mathrm{Li} 4 \%$ magnesium alloy based on experimental results of Cazacu et al. (2006). A linear interpolation is used to take into account of the distortion of the yield surface. The shape and the level of the predicted forming limit diagrams are strongly sensitive to the effective instability parameter, distortion and viscosity, especially in bi-axial stretching. The level of limit strains predicted 
Mohamed Yassine JEDIDI, Mohamed BEN BETTAIEB, Farid ABED-MERAIM, Mohamed Taoufik KHABOU, Anas BOUGUECHA, Mohamed HADDAR

by the initial imperfection approach is inferior to limit strain predicted by the perturbation method. Consequently, with the linear perturbation, ductility limit of $\mathrm{Mg}-\mathrm{Li} 4 \%$ increases. The implementation of the proposed implicit integration algorithm into a finite element code using damage model and non-associated model will be the subject of the future investigations.

\section{References}

Boudeau, N., \& Gelin, J. C. (1992). Finite element simulation of the ductile fracture in 3-D sheet metal forming process. Journal of Materials Processing Technology, 32(1-2), 521-530.

Boudeau, N., Gelin, J. C., \& Salhi, S. (1998). Computational prediction of the localized necking in sheet forming based on microstructural material aspects. Computational Materials Science, 11(1), 4564.

Boudeau, N., Lejeune, A., \& Gelin, J. C. (2002). Influence of material and process parameters on the development of necking and bursting in flange and tube hydroforming. Journal of materials processing technology, 125, 849-855.

Bochniak, W., Korbel, A., Ostachowski, P., \& Łagoda, M. (2018). Plastic flow of metals under cyclic change of deformation path conditions. Archives of Civil and Mechanical Engineering, 18(3), 679-686. Cazacu, O., Plunkett, B., Barlat, F., 2006. Orthotropic yield criterion for hexagonal closed packed metals. Int. J. Plast. 22(7), 1171-1194.

Dudzinski, D., \& Molinari, A. (1991). Perturbation analysis of thermoviscoplastic instabilities in biaxial loading. International Journal of Solids and Structures, 27(5), 601-628.

Fressengeas, C., \& Molinari, A. (1987). Instability and localization of plastic flow in shear at high strain rates. Journal of the Mechanics and Physics of Solids, 35(2), 185-211.

Jedidi, M. Y., Bettaieb, M. B., Bouguecha, A., Abed-Meraim, F., Khabou, M. T., \& Haddar, M. (2020) Prediction of the Ductility Limit of Magnesium AZ31B Alloy. In Advances in Materials, Mechanics and Manufacturing (pp. 182-193). Springer, Cham. (a).

Jedidi, M. Y., Bettaieb, M. B., Abed-Meraim, F., Khabou, M. T., Bouguecha, A., \& Haddar, M. (2020). Prediction of necking in HCP sheet metals using a two-surface plasticity model. International Journal of Plasticity, 128, 102641. (b)

Kondori, B., Madi, Y., Besson, J., Benzerga, A.A., 2018. Evolution of the 3D plastic anisotropy of HCP metals: Experiments and modeling. Int. J. Plast. doi.org/10.1016/j.ijplas.2017.12.002.

Marciniak, Z., \& Kuczyński, K. (1967). Limit strains in the processes of stretch-forming sheet metal. International Journal of Mechanical Sciences, 9(9), 609IN1613-612IN2620.

Molinari, A. (1985). Instabilité thermoviscoplastique en cisaillement simple. Journal de mécanique théorique et appliquée, 4(5), 659-684.

Plunkett, B., Lebensohn, R.A., Cazacu, O., Barlat, F., 2006. Anisotropic yield function of hexagonal materials taking into account texture development and anisotropic hardening. Acta Mater. 54(16), 4159-4169.

Toth, L. S., Hirsch, J., \& Van Houtte, P. (1996). On the role of texture development in the forming limits of sheet metals. International Journal of Mechanical Sciences, 38(10), 1117-1126.

Wu, S.H., Song, N.N., Pires, F.M.A., Santos, A.D., 2015. Prediction of forming limit diagrams for materials with HCP structure. Acta Metall. Sin. 28(12), 1442-14.

Zaera, R., Rodríguez-Martínez, J. A., Vadillo, G., Fernández-Sáez, J., \& Molinari, A. (2015). Collective behaviour and spacing of necks in ductile plates subjected to dynamic biaxial loading. Journal of the Mechanics and Physics of Solids, 85, 245-269. 